\title{
A RACIONALIDADE, A CULTURA E O ESPÍRITO EMPRESARIAL
}

\author{
Paola Cappellin* \\ Gian Mario Giuliani*
}

Resumo: O artigo busca a articulação das noções de racionalidade, interesse, valores e cultura. Na sociologia weberiana, a racionalidade é associada ao capitalismo moderno e ao "espírito empresarial". Outros autores (Off, Hirschman, Veblen, Simmel, Elster) têm discutido quão difícil é a realização do encontro entre o "moderno" e o "racional". Destas análises, é possível apontar duas questões relevantes para o estudo da problemática empresarial. A primeira é que o desenvolvimento do capitalismo tem, de fato, imposto e universalizado a racionalidade econômica, porém não a tornou nem homogênea nem independente da influencia da cultura. A segunda diz respeito à influência dos valores sobre a racionalidade econômico-empresarial, formulando normas e regras que dão fundamento e orientam as ações e iniciativas para a manutenção do patrimônio e para a realização do lucro. Pode-se então falar de "cultura de empresa" que leva a refletir sobre um conjunto de formas de regulação cultural das empresas, formas que são herdadas de uma longa história industrial e que devem ser ponderadas por produzirem efeitos sistemáticos. Com isso, o "espirito empresarial", como expressão da racionalidade capitalista, pode ser enriquecido por dimensões que incluem um conjunto de práticas e valores fundados em referências advindas de diferentes ambientes, familiar, territorial, político e social. Conclui-se que as empresas não podem ser vistas exclusivamente sob a ótica organizacional, já que estas são inseridas em uma cultura de uma sociedade, de uma região, das tradições e organizações profissionais. Também, as empresas conseguem ter influências sobre diversas dimensões da vida social, estabelecendo elos e trocas com as instituições, grupos e comunidades.

Palavras-chave: Sociologia da Empresa, racionalidade.

* Os autores são professores do Programa de Pós-Graduação em Sociologia e Antropologia (PPGSA) do Instituto de Filosofia e Ciências Sociais (IFCS) da UFRJ. 
A noção de "racionalidade" está ligada a diversas visões teóricas e a uma série de conceitos que tornam difícil uma definição unívoca. Na Sociologia weberiana, o moderno é associado à racionalidade nos processos organizativos e produtivos que, baseados no cálculo da rentabilidade capitalista e na impessoalidade, avançam combatendo e substituindo formas econômico-sociais fundamentadas na tradição, sobretudo no poder personalizado e no patrimonialismo (Weber, 1944). Este processo estaria destinado a abranger todas as esferas da sociedade e a instituir a racionalidade como definitiva fonte de orientação das ações de todos os indivíduos. Até os anos 60, na maioria das análises brasileiras emergia a preocupação em pôr em evidência a natureza conflitante das dimensões tradicionais com o "espírito empresarial", este, sim, racional e moderno, fundamentado na rentabilidade e no trabalho livre.

As características mais marcantes de relações econômicas e sociais de tipo tradicional, opostas ao racional e ao moderno, eram identificadas nas diversas formas das relações sociais e de trabalho mantidas e no poder social e político exercido regional e localmente pelos empresários. Mais particularmente, o controle personalizado sobre o mercado, sobretudo da mão-de-obra, e a busca da riqueza, não tanto como estímulo para a realização de lucros, mas como conjunto de "bens raízes" capazes de aumentar o prestígio e poder dos donos (Faoro, 1989). Porém esta perspectiva da "modernidade" e de sua incompatibilidade com as tradições, já tem sido objeto de sérias revisões (Giddens, 1991), e estudos têm mostrado como é possível a convivência nas práticas empresariais de aspectos da modernidade combinados com dimensões da tradição (Cappellin e Giuliani, 1999). ${ }^{2}$

O desenvolvimento de diferentes estilos de "ser empresário" no Brasil é sugerido por autores (Morel et al., 1993) que ressaltam a especial ênfase posta na retórica modernizadora própria do período pós-Constituinte de 1988, sobretudo pelo que se refere à liberalização econômica e ao debate sobre a reformulação das relações capitaltrabalho. Outro autores (Diniz e Boschi, 1993) têm sublinhado as novidades no plano tanto das relações entre os empresários, o Estado e o mundo do trabalho, como da atuação dos primeiros no processo 
político de renovação. Tais novidades, no entanto, não seriam suficientes para indicar a existência de um novo perfil de atuação empresarial por uma série de razões. Em primeiro lugar, pela ausência de um modelo de desenvolvimento de produção industrial e pela falta de diretrizes por parte do governo capazes de estimular um novo patamar de desenvolvimento, tal como foi o caso, por exemplo, da indústria automobilística nos anos de 1950 ou do setor de bens de capital nos anos de 1970. Também porque as novidades apresentamse isoladas e, portanto, incapazes de apontar para uma possível tendência de desenvolvimento nesse sentido. Em seguida, porque o modelo de representação do empresariado permanece híbrido, permitindo a coexistência de um formato corporativo e de um modelo autônomo constituído pelas associações baseadas em "afinidades eletivas". ${ }^{3}$ Finalmente, porque a incapacidade de superar enfoques setoriais e corporativos torna frágeis e localizados aqueles enfoques mais abertos à prática da concertação e mais comprometidos com a mudança da situação dos trabalhadores. Os autores acabam reconhecendo que os estilos e as práticas de atuação da classe empresarial revelam-se bastante diversificados, mostrando a coexistência de diferentes posições e posturas ideológicas.

No nível geral, já Offe (1987) havia sugerido que o encontro entre o "moderno" e o "racional" que, em teoria, devia acontecer naturalmente, teria na realidade sérias dificuldades para se realizar. $\mathrm{O}$ autor aponta para a incapacidade de o processo modernizador alcançar todas as esferas da vida social. Este processo não só tem produzido fortes diferenças entre países e entre regiões do mesmo país, mas também tem colocado sérios problemas para as próprias sociedades consideradas "mais modernas". Nesse sentido, sublinha o autor, as múltiplas dimensões (institucionais, organizativas, culturais) da sociedade tendem a se modernizar tornando-se autônomas de maneira não combinada, e, às vezes, conflitantes entre si. O resultado é que as partes acabam se modernizando em prejuízo da modernização do todo.

É, portanto, possível apontar duas questões, a nosso ver relevantes, para o estudo da problemática empresarial. A primeira é que o desenvolvimento do capitalismo tem imposto e universalizado de fato a racionalidade econômica, porém não a tornou nem 
homogênea nem independente da influência da cultura e dos âmbitos em que se organizam e se especificam as relações sociais (família, grupo, território, nação), e muito menos a deixou imune de influências que ela não pode controlar e que a deformam ou a contrastam. A segunda, como natural aprofundamento da primeira, diz respeito à influência dos valores sobre a racionalidade econômico-empresarial, formulando regras e normas que dão fundamento e orientam as ações e iniciativas para a manutenção do patrimônio, a acumulação do capital e a realização do lucro.

Para dispor de maiores elementos de reflexão sobre estas questões, parece interessante revisitar algumas contribuições "mais antigas" e quase esquecidas, que tratam de temáticas importantes para a discussão da racionalidade econômica e empresarial, tais como: o interesse econômico, o dinheiro e as atividades produtivas e improdutivas. A seguir, uma análise da literatura mais atual e pertinente à nova modernidade.

\section{A noção de interesse}

O interesse econômico foi sempre considerado o fundamento de todas as atividades empresariais. As diferentes apreciações sociais desta noção são tratadas por Hirschman, em The passions and the interest: political arguments for capitalism before its triumph, obra escrita entre 1972 e 1976, ${ }^{4}$ quando está pensando na América Latina, principalmente preocupado em desfazer a idéia corrente de que o crescimento econômico traria correlatos políticos mais favoráveis. Seus escritos criticam tanto as políticas revolucionárias, como as políticas chatamente reformistas, ambas consideradas ineficazes. (Mendolesi, 1990)

O autor discorda da perspectiva marxiana que vê no desenvolvimento do capitalismo uma luta contra o sistema de idéias feudais, e se propõe demonstrar que o novo surgiu do velho e que a transição entre as duas formações sociais foi um processo endógeno. Parte da pergunta de Weber, formulada na consagrada obra A ética protestante e o espírito do capitalismo: como pôde o comércio se tornar, de uma atividade indigna, em uma atividade digna e 
civilizadora? Com efeito, na filosofia medieval agostiniana, as paixões concentradas na ânsia pelo dinheiro, desejo de poder e desejo sexual eram consideradas insanas e destruidoras, tanto dos indivíduos, como da convivência em sociedade. A única paixão à qual era dado um valor social compensador era o "desejo de glória". No entanto, Hirschman se propõe seguir um caminho diferente do de Weber. Não busca as consequiências não intencionais das ações humanas, como Weber fez na sua hipótese da combinação de uma ética religiosa com o espírito capitalista. Ao contrário, Hirschman procura descobrir como certas idéias orientam para objetivos que estão claramente definidos nas intenções dos atores.

Nessa perspectiva, o autor observa que entre a Renascença e o Século XVII surgiu na cena o "homem como ele é", obscurecendo o homem como "deveria ser" (ver Maquiavel, Hobbes, Galileu e Spinoza) e, para controlar as paixões destruidoras desse homem já não bastavam mais a filosofia moral, a religião e nem o Estado. Começa a tomar forma a idéia de que as paixões podiam ser combatidas por outras paixões, distinguindo assim entre "paixões domadoras" e "paixões a serem dominadas". ${ }^{5}$

No Século XVIII, as paixões são reabilitadas, passando a ser consideradas revigorantes e até úteis, permitindo a afirmação da noção de "interesse", como a paixão pelo dinheiro, pela riqueza. O interesse pode englobar todas as aspirações humanas, porém revela "o cálculo" para realizar tais aspirações. Como um novo paradigma, o interesse passa a explicar as ações humanas e torna-se um componente natural do homem, uma força reguladora externa aos indivíduos. O interesse apresenta vantagens para a vida social: oferece previsibilidade e constância. Com efeito, de um lado fornece regras externas às subjetividades, uniformizando-as; de outro, o interesse torna-se igual à razão, já que ninguém seria tão irracional a ponto de agir contra seus interesses. Assim, a anteriormente condenável "fome de lucro" torna-se uma virtude, porque implica previsibilidade e constância. Estas dimensões, apontadas por Hirschman, acabam se combinando com a idéia de progresso ao mesmo tempo econômico, social e cultural que o desenvolvimento do sistema de empresas automaticamente levaria consigo porque ao interesse é atribuída uma outra qualidade: a de ser uma paixão inofensiva. Este se tornaria um "desejo calmo" 
que age calculada e racionalmente. Ganhar dinheiro seria uma atividade inocente, inócua e civilizadora; o comércio uma atividade doce, polida, gentil, antinômica à violência.

Os Séculos XIX e XX, com suas revoltas e revoluções anticapitalistas, anticolonialistas e antiimperialistas, contrastaram duramente este legado, mas não o destruíram, já que ainda hoje a renúncia à maximização do "auto-interesse" é considerada como uma clara prova de comportamento irracional. Tal percepção tem levado economistas do peso de Sen a dizer que "a natureza da economia moderna foi substancialmente empobrecida pelo distanciamento crescente entre economia e ética" e a lamentar a difusão "daquela exótica concepção moral conhecida como egoísmo ético" (Hirschman, 1999, p. 21).

\section{O dinheiro na teleologia}

Se interesse pressupõe um cálculo e acaba eqüivalendo à racionalidade, o dinheiro torna-se um instrumento fundamental para a realização dos interesses. O dinheiro, no entanto, consegue ir muito além de um simples instrumento para alcançar as finalidades. Esta temática é tratada por Simmel $^{6}$ em sua obra mais sistematizada, $A$ filosofia do dinheiro, publicada em 1900. A obra tem atraído quem busca vieses no marxismo não ligados estritamente à relação estruturasuperestrutura. Porém há algo original em Simmel: de um lado, para analisar as consequiências positivas e negativas da economia monetária não se refere diretamente ao processo de industrialização e ao desenvolvimento capitalista-industrial; de outro, concentra sua atenção nas relações de intercâmbio e não nas relações de produção. Considera importante reduzir o processo econômico ao que acontece na cabeça de cada sujeito econômico, sendo que em todo intercâmbio econômico ocorre a mesma percepção subjetiva de sacrifício ou de lucro na cabeça dos indivíduos. $O$ intercâmbio não está na base somente da economia, mas também da própria sociedade humana, já que toda interação humana é um intercâmbio, como toda conversa, afeto, jogo, ou olhar. 
No Capitulo III, Simmel refere-se ao que mais nos interessa: 1) às consequiências das relações monetárias sobre a ação intencional; 2) às relações meios-fins, chamadas de série teleológicas, onde os meios tornam-se fins. $\mathrm{O}$ autor considera que diferentemente do animal, que age movido pelas pulsões e visando diretamente à satisfação, o homem considera satisfatória sua ação, que também é movida pela pulsão, somente após ter avaliado o resultado. Portanto, quando se estabelece uma série teleológica é porque já se conhece a relação causal entre os elementos. A "consciência causal" anda junto com a "consciência teleológica". Nas sociedades complexas, as séries teleológicas são mais longas e são mais complexos os instrumentos para alcançar os fins.

Nas séries teleológicas, o dinheiro desempenha um papel muito singular. Como o dinheiro aparece neutral, também aparece indiferente diante dos fins e das pessoas; mais ainda, em virtude de sua universalidade e falta de conteúdo, o dinheiro tem uma relação totalmente ilimitada com os fins. À medida que a economia se monetariza, o dinheiro pode se converter em fim absoluto. Devido a tal inversão de meio para fim, no início a economia monetária cria fenômenos extremos e contrários: a pobreza ascética e a prodigalidade. No apogeu da economia monetária cria fenômenos como o cinismo (que nivela os valores mais altos com os mais baixos), a indiferença e o tédio, fruto do desinteresse pela natureza das coisas e pelas qualidades específicas, sentimentos que levam a buscar satisfação na velocidade da troca.

Se o dinheiro é indiferente às qualidades pessoais, o autor se pergunta qual é seu papel no desenvolvimento da liberdade individual. Com relação à liberdade, o papel do dinheiro é multidimensional e até ambíguo. Ele cria relações entre os indivíduos, sem perturbá-los pessoalmente. Dá uma maior liberdade a seu possuidor quando comparado, por exemplo, a quem possui terra ou bens materiais, já que o dinheiro é mais fácil de se intercambiar e já que mantém separada a propriedade da pessoa (separação desconhecida na Idade Média). Nas relações de trabalho, permite contratar somente a força de trabalho e não a pessoa. Torna mais autônomo o indivíduo que antes dependia totalmente de seu grupo. Permite a seu possuidor participar de uma ampla gama de associações sem compromisso ou 
dedicação pessoal. Finalmente, o valor de uma soma de dinheiro vale o valor dos produtos que pode comprar mais o valor da liberdade de escolha. Assim, o dinheiro possui um efeito atomizador, mas também unificador; após ter destruído todas as relações entre os indivíduos, restabelece relações entre elementos que jamais teriam tido conexão sem ele. A objetivação das interações humanas encontra seu ponto mais alto nos interesses econômicos puramente monetários e, também, na intelectualização e funcionalização das relações. Para Simmel, no entanto, o dinheiro não é somente um dos principais instrumentos racionalizadores da vida social moderna, mas também acaba produzindo novas dimensões de irracionalidade. Com efeito, o cálculo monetário, nascido com a Era Moderna leva ao "ideal calculatório", isto é, a conhecer o mundo como um imenso problema aritmético e leva à preponderância da cultura objetiva (os artefatos dos homens) sobre a subjetiva (as percepções individualizadas que os homens têm de tais artefatos e das relações sociais), provocando o que chama de "tragédia da cultura" ou "patologia da cultura", isto é, um hiato crescente entre os desejos e aspirações e as condições e possibilidades. $^{7}$

\section{Atividades produtivas e improdutivas}

A difusão do "interesse" como paradigma e do cálculo como método do agir na sociedade moderna, parece ainda sofrer interferências de elementos culturais da tradição, de tal forma que a racionalidade muitas vezes se impõe mais como uma "racionalização". Exemplo claro são as formas como são vividas culturalmente as ocupações, o trabalho e o consumo.

Esta temática é tratada por Veblen em sua obra A teoria da classe ociosa, publicada em $1899 .{ }^{8}$ Crítico com relação à situação econômica e à economia clássica, inspirado no evolucionismo, formula uma teoria da ação inter-individual parecida com a de Weber, mesmo que não tão rica. Para Veblen, o homem é um centro de atividades impulsivas e teleológicas e sempre busca alguma finalidade. Suas ações são impulsionadas pelo instinto "da eficiência" que se expressa por uma demonstração de força, bravura ou competência alimentada 
por um natural sentimento de emulação. Nos estágios em que prevalece a cultura pacífica, a emulação leva os indivíduos a competir no trabalho e na produção, incentivando seu orgulho em superar sempre os outros e a si mesmos. Com a instituição da propriedade privada, a emulação impulsiona uns a se distinguirem dos outros na base da riqueza dando forma ao que o autor chama de "classe ociosa". Esta compete no plano da abstenção do trabalho produtivo e caracteriza os estágios bárbaros baseados na luta e na exploração e onde prevalece a cultura belicosa. ${ }^{9}$

Nessa obra, o autor quer debater o lugar e o valor da classe ociosa à luz da sociedade moderna. Para isso, observa que diferentes períodos históricos apresentam diferentes classes ociosas (guerreiros, sacerdotes, nobres), no entanto, estas encontram seu maior desenvolvimento nos mais altos degraus da civilização bárbara. Todas as classes ociosas tem em comum o fato de não serem produtivas. Podem se dedicar ao governo, à guerra, às práticas religiosas, ao esporte, mas não à produção e ao trabalho. Com ela nasce a discriminação das atividades como "dignas" e "não dignas". São dignas as que levam para a fama e a glória; são indignas as que são quotidianamente necessárias, as que implicam servilismo e submissão.

Veblen amplia o tema da tensão entre o instinto da eficiência e as consequiências da emulação pelo dinheiro até compreender os contrastes entre os aspectos produtivos e os aspectos predadores do capitalismo moderno, mais especificamente, entre a produtividade da indústria e as atividades do comércio e da finança, que considera predatórias. Expressões importantes relativas à classe ociosa são a "ociosidade vistosa" e o "consumo vistoso". À raiz da ociosidade vistosa está a questão da emulação financeira. Para a classe ociosa não basta ser rico e poderoso, tem que pôr esta condição em evidência. A divisão arcaica do que é uma ocupação vil e o que é uma ocupação honrada, ainda hoje é forte. Existem trabalhos que as classes altas não fariam nem forçadas, devido a um agudo sentimento de "indecência social". Durante os primeiros períodos da fase industrial pós-rapina, a ociosidade é a prova conclusiva do poder financeiro e o indicador convencional da respeitabilidade. O trabalho é indigno, porque signo de pobreza; deve ser evitado porque é indigno para homens capazes. 
Para Veblen, as ocupações típicas das classes ociosas ainda hoje são as mesmas: o governo, as guerras, o esporte, a prática religiosa. Alguém pode dizer que hoje estas são produtivas, mas o fato é que os motivos que levam a exercê-las, não visam aumentar a riqueza através de um esforço produtivo. Não trabalhar não é somente um ato meritório, mas também um requisito de respeitabilidade, a expressão de um alto nível social. Os nobres decaídos, perdem sua riqueza mas não podem trabalhar. Por outro lado, a ociosidade não significa indolência ou ignávia; significa consumo improdutivo do tempo, devido tanto à indignidade do trabalho, como à vontade de demonstrar a própria capacidade financeira. Os signos de uma ociosidade passada assumem a forma de bens imateriais: o conhecimento de línguas mortas, da literatura, da música, da pintura, das ciências ocultas, o falar correto. Todas estas são atividade que demonstram que o tempo não foi gasto em trabalhos produtivos. Outras práticas ligadas não ao campo do saber mas à habilidade física, às boas maneiras, à cortesia, às regras formais da etiqueta (que opõem o rústico e o grosso ao fino), são mais fortes quando a ociosidade está em voga. A decadência da etiqueta entre os homens de negócio, para o autor, demonstra que o decoro só prospera em regime de casta. O fundamento econômico mais profundo está no fato de que as boas maneiras estão ligadas ao ócio, ao consumo improdutivo do tempo, sem o qual estas não podem ser aprendidas. A boa educação exige tempo, aplicação, despesas e disponibilidade financeira. $\mathrm{O}$ decoro é um dever para quem aspira à respeitabilidade financeira.

Também, para que a solidez financeira resulte evidente, os "ociosos" precisam mostrar que há gente que trabalha para eles (domésticos, empregados), assim como ostentar a posse de muitos objetos "inúteis", como troféus, brasões, medalhas. Objetos de consumo caro são considerados nobres e honoríficos e isto constitui a base do consumo vistoso. A classe ociosa é aquela que pode distinguir entre o que é honrado e o que não é. O consumo e a ociosidade constituem investimentos em reputação. Na pequena burguesia, o homem não pode ter pretensões de ociosidade, mas a atividade ociosa da mulher tende a demonstrar que esta não precisa produzir. É, para Veblen, a lei econômica do esforço supérfluo. A mulher tem que ter gastos vistosos, pela honra da casa e do chefe. O consumo deve ser de 
coisas supérfluas, deve ser um desperdício para ser honrado. Não há méritos no consumo necessário. A ociosidade vistosa e o consumo vistoso têm em comum o desperdício: a primeira, de tempo e energias; o segundo, de bens e dinheiro. A escolha de um ou de outro é somente questão de estratégia publicitária, depende das circunstâncias e das pessoas que se quer influenciar.

Poderíamos pensar, observa Veblen, que o desenvolvimento industrial levaria o consumo vistoso a prevalecer sobre a ociosidade vistosa, até eliminá-la. Mas este modelo não estaria totalmente correto. A antiga distinção entre classes nobres e não nobres apoiava-se na distinção entre ocupações honrosas e degradantes e esta distinção tornou-se norma. É verdade que o declínio da ociosidade, como signo de riqueza, pode ter contribuído em parte para a crescente eficácia do consumo vistoso. Porém, tal crescimento pode ser atribuído também ao incremento do instinto da eficiência, isto é, ao desprezo por todo desperdício, tanto de substância, como de energia. O instinto da eficiência está presente em todos os homens, e os faz naturalmente amar o trabalho porque dá resultados e os leva a detestar o que é inútil. Tal instinto, para Veblen, deveria ser o grande racionalizador, o demolidor da tradição, a possibilidade de solução dos problemas. No entanto, na sociedade moderna, o instinto da eficiência pode começar a sofrer "desvios". Por exemplo, pode tornar meritórios todos os gastos para o consumo destinado a aumentar a auto-estima, ou também pode transformar os gastos no exercício de "deveres sociais" (como a freqüência de clubes e associações), em si inúteis, em gastos providos de alguma eficácia econômica, satisfazendo assim ao instinto de eficiência através de um processo de racionalização. Esta é, para Veblen, a caraterística distintiva da classe ociosa moderna: a ociosidade sem sentido torna-se detestável, porém continua vivo o padrão de honradez, prestígio e poder ligado às ocupações não produtivas.

\section{A escolha racional}

A racionalidade, fundamento da sociedade moderna, parece, portanto, provida de uma complexidade que a torna frágil e insegura, 
ainda ligada a uma cultura cheia de desejos e crenças, de tradições e irracionalidade. Esta temática é tratada por Elster ${ }^{10}$ em diversas obras e, particularmente em uma espécie de trilogia.

Em 1979, Elster publica Ulysses and the sirens: studies in rationality and irrationality. Nessa obra, fala da racionalidade imperfeita, dos truques e mecanismos adotados para que a racionalidade dos atores seja, por várias razões, diferente da escolha racional teórica. O maior exemplo, que confere o título ao livro, é o comportamento de Ulisse, pois sabendo que ao ouvir as sereias tornarse-ia irracional, escolhe um mecanismo que bloqueia a irracionalidade e o obriga a ser racional. Para Elster, os homens, apesar de não serem racionais, querem sê-lo, por isso criam suas próprias constrições.

Em 1983, em Sour grapes: studies in the subversion of rationality, Elster reflete sobre os condicionantes objetivos externos e sobre a formação das preferências, as quais são habitualmente negligenciadas pelos economistas. Em princípio, a conotação do termo "racionalidade" vai desde as noções de "eficiência" e "coerência" até as de "autonomia" e de "autodeterminação", dando a impressão de que a racionalidade diz ao indivíduo o que ele deve fazer e, se assim não o fizer, será irracional. Mas Elster acha que a racionalidade não pode fornecer critério de escolha e só pode excluir algumas alternativas. Considera que os condicionantes são importantes, já que podem moldar os desejos e até as crenças. Os desejos podem ser distinguidos com base em sua origem (autônomos ou não autônomos) e com base no seu conteúdo (éticos ou não éticos). No nível da origem, podemos ter a adaptação das preferências às condições do possível (a raposa que não consegue comer a uva, acaba dizendo que a deixa porque é verde); podemos ter a adaptação das preferências às dos outros (conformismo) e, também, podemos ter preferências "contraaditivas", que levam ao anticonformismo e à obsessão pela novidade. Nesta obra o autor mostra como a racionalidade pode ser subvertida quando as crenças são determinadas pelos interesses. Com efeito, podemos não ter a capacidade de tirar conclusões lógicas de nossas crenças, seja por falta de conhecimentos completos, seja por pressões afetivas (por exemplo: embora já tenhamos provas da desonestidade de algum amigo, não acreditamos). Podemos também ter a ilusão de 
pensar que as coisas são como nós as desejamos (wishful thinking). Elster contesta as idéias, difundidas no Século XVIII, que associavam interesse a racionalidade, assim como bem tem mostrado Hirschman. Para esta posição, o autor encontra apoio na teoria do empresário capitalista de Shumpeter (1954), segundo a qual o capitalismo funciona porque induz a expectativas irreais quanto ao sucesso e, portanto, mobiliza muito mais energias do que seriam empregadas por espíritos sóbrios.

Em 1989, publica Solomonic judjements discutindo os limites da racionalidade e, portanto, os limites da teoria da ação racional, tanto no plano positivo como no plano normativo. As limitações vêm de dois lados: a) do lado do comportamento efetivamente irracional dos homens, isto é, de sua incapacidade de explorar a teoria; b) do lado da indeterminação da teoria, isto é da incapacidade desta determinar um único resultado, mas admitir vários.

Estas problemáticas são recuperadas em Nuts and bolts for de social sciences, obra publicada em 1989 e na qual caracteriza os microfundamentos da sociedade, isto é, as engrenagens da sociedade, os desejos e as crenças que geram as interações e as dinâmicas coletivas. Os instrumentos desta busca são a investigação empírica e uma série de instrumentos teóricos, entre os quais as teorias da socialização, a teoria da escolha racional (para o indivíduo) e a teoria dos jogos (para o coletivo). Para o Elster, o objetivo último é compreender, em um fenômeno empírico, a combinação exata das dimensões antinômicas: racionalidade/irracionalidade, egoísmo/ altruísmo, intencionalidade/hábito. A teoria da ação racional descobre paradoxos, contradições e incongruências (assim como para Weber o faz seu famoso recurso metodológico, o tipo ideal) e mostra como a intencionalidade não pressupõe a racionalidade.

A escolha racional, para Elster, reuniria três condições: 1) é o melhor modo de realizar os desejos de uma pessoa, dadas suas crenças; 2) essas crenças devem ser ótimas para essa pessoa; 3) deve juntar uma quantidade ótima de evidências, já que pressupõe uma avaliação dos meios, das possíveis conseqüências e uma escolha entre diferentes alternativas. A racionalidade, portanto, baseia-se na crença mais racional fundada sobre as provas disponíveis. Esse tipo de definição 
não só leva a um aprofundamento da definição weberiana, ${ }^{11}$ mas revela toda a fragilidade da noção de racionalidade, já que a cada passo do processo de definição da escolha abre uma série de possibilidades que tornam o resultado não previsível. Vejamos tais possibilidades.

Em primeiro lugar, pelo que se refere à relação racionalidadedesejo, o autor observa que os desejos podem se orientar ao presente e sacrificar o futuro, ou podem também se orientar ao futuro sacrificando o presente, sem que se possa dizer qual orientação seria racional ou irracional. No máximo podem ser detectados racionalmente os desejos logicamente incoerentes (por exemplo, desejar comer muito e querer ser magro).

Em segundo lugar, a escolha racional é sempre instrumental. É guiada pelos resultados da ação, busca os melhores meios para alcançar fins dados e, finalmente, avalia e escolhe o que considera ser os melhores meios. Sendo assim, a escolha racional não é infalível, já que as pessoas escolhem os meios que acreditam serem os melhores, enquanto poderiam não sê-lo realmente. A escolha racional também se baseia em crenças fatuais que são simples probabilidades (plantar para colher; investir para ganhar, etc.). Finalmente a escolha racional elege uma alternativa, em geral, a mais conveniente dadas certas condições. Em geral, combina teoricamente custos, benefícios e riscos, sendo que a decisão acontece sob a pressão de um destes elementos: alguém pode suportar custos maiores, outro está disposto a correr riscos mais altos na busca de benefícios maiores; outros ainda são mais cautos e se contentam com menos.

Em terceiro lugar, a racionalidade pode falhar, não só quando faltam informações ou tempo para coletá-las, mas também quando a escolha racional é objetivamente indeterminada. Por exemplo, um empresário escolhe vender menos com maior margem de lucro ou vender mais com menor margem de lucro? Do ponto de vista da racionalidade é indiferente, porém, não o é do ponto de vista de sua relação com os empregados ou com os consumidores. Os indivíduos, em geral, não reconhecem a indeterminação e buscam uma justificação qualquer; em geral acabam racionalizando ou se orientando pelo 
wishful thinking, pela crença de que as coisas estão de fato como eles gostaria que estivessem.

Finalmente, da escolha racional podem decorrer conseqüências não intencionais, as quais, sobretudo, decorrem das características do desejo, isto é, deste estar orientado ao futuro, ou orientado ao presente. Tais conseqüências podem ser boas ou más para o conjunto da sociedade. As más podem resultar de uma estrita orientação ao presente (a busca do lucro fácil e imediato pode prejudicar o empresário, seus funcionários e os consumidores), sendo as piores as que o autor chama de "contrafinalidades" (desmatar para obter uma área maior para plantar pode levar a perder terra pela erosão e à seca; fazer filhos para ter mão-de-obra ou para cuidar da velhice leva à superpopulação). Ao contrário, as boas são aquelas onde os desejos individuais ajudam a todos, como uma espécie de "mão invisível" (a empresa se expande e todos ganham; os moradores cuidam de seus jardins e calçadas e o bairro fica lindo). $\mathrm{O}$ autor alerta para que as conseqüências não intencionais não sejam usadas como explicação das ações que as causaram, já que o futuro não pode causar o passado; porém, observa que tais conseqüências podem causar uma repetição da ação.

Para Elster, a escolha racional depende dos contextos: é boa para o indivíduo quando age só; mas, na interação com outros indivíduos, tal escolha pode resultar prejudicial para si mesmo e para os outros. Nas ações coletivas, o indivíduo encontra dilemas, problemas sem solução, porque o resultado de suas ações depende da ação dele e dos outros. Na ação coletiva a racionalidade individual pode levar a desastres coletivos (uma empresa pode ter custos muito reduzidos e altos lucros, mas todas não podem; seria possível chegar mais rapidamente ao trabalho indo de carro, mas se todos forem de carro, o tempo gasto será maior). Para mostrar que em um contexto coletivo a indeterminação é muito maior, o autor recorre à teoria dos jogos. ${ }^{12}$ Se, por exemplo, aplicarmos tal teoria à ação de um empresário frente à escolha de introduzir inovações para reduzir seus custos com salários, podemos ver que a racionalidade da escolha permanece indefinida. Com efeito, já que seus pares são atores livres, podem ocorrer dois resultados alternativos: a) se ele acreditar que 
todos inovarão, ele poderá não inovar, já que os salários baixarão de qualquer maneira; b) se acreditar que ninguém inovará, ele deverá inovar, já que os salários irão subir. Nesse contexto qual das escolhas pode ser definida racional? Ambas ou nenhuma, já que o racional finalmente acaba resultando de uma crença.

Elster busca superar este impasse restabelecendo a relação entre escolha racional e a finalidade da ação em um contexto coletivo através daquilo que chama de "conduta cooperativa" e "nãocooperativa". As pessoas que fazem aquilo que é o melhor se todos o fizerem, para o autor seriam os "cooperadores" e os outro, os "nãocooperadores". A pergunta neste caso é: cooperar e agir contra o próprio interesse é irracional? O que acontece na realidade são duas situações extremas: o não-cooperador-unilateral consegue os melhores benefícios; o cooperador-unilateral consegue os piores resultados. $\mathrm{O}$ problema da racionalidade na ação coletiva consiste na dificuldade com que as pessoas cheguem a cooperar para seu benefício mútuo. Elster identifica as seguintes condições em que é mais fácil atingir a cooperação mutuamente benéfica: quando há auto-interesse na cooperação, quando os ganhos da cooperação são altos e os da não cooperação baixos, quando a perda da não-cooperação unilateral é pequena e, sobretudo, quando o indivíduo está convencido de que os outros são tão racionais e bem informados sobre a situação quanto ele e, portanto, podem entender que cooperando todos sairão ganhando.

\section{A racionalidade e a cultura de empresa}

Temos visto como a Sociologia pode alcançar uma compreensão da sociedade contemporânea à medida que, além de descobrir diferentes formas de racionalidade que vão além, ou ao lado, da "racionalidade econômica", também aponta para dimensões que podem torná-la mais complexa e problemática. No caso da gestão das empresas, mesmo caracterizada pela racionalidade com finalidade de lucro, diferentes podem ser as formas pelas quais tal finalidade é alcançada e de diversa natureza podem ser as dimensões que intervêm nos processos de escolhas. Geralmente, são dimensões de tipo cultural 
(religiosas, locais, tradicionais e simbólicas), de natureza afetiva (familiares) ou até ideológica, sendo que na sociedade contemporânea já não se consideram mais "irracionais", à moda de Weber, mas aparecem como componentes da racionalidade moderna, própria de indivíduos fragmentados, descontínuos e incongruentes. Para Touraine (1984) a empresa ainda é um agente da modernidade, definida esta como racionalização, no entanto considera que a crise cultural da modernidade redimensiona, reduzindo-o, o triunfo do cálculo e da autoridade racional legal e, por isso, duvida que todos os atos que constituem o essencial da vida das empresas (produzir eficientemente, responder às demandas do mercado, elevar o lucro, diversificar os investimentos) respondam integralmente ao "ideal calculatório" temido por Simmel, ou que sejam todas expressões da pura racionalidade econômica.

A Sociologia do Trabalho, nos anos de 1980, em face da globalização, acelera o debate sobre a concorrência, a competividade e a crise do modelo rígido de organização fechada, revitalizando o interesse para os estudos da empresa e dando forma à Sociologia da Empresa. Esta, como especialização da Sociologia das Organizações, considera a empresa como uma organização cujo papel econômico não esgota sua capacidade de intervenção institucional. A nova perspectiva passa a contribuir significativamente para a compreensão dos efeitos da crise econômica, das flutuações das fontes de empregos e, sobretudo, da capacidade das empresas serem um centro irradiador e estabilizador das formas de reprodução social (Bernoux, 1995). Este período corresponde às fortes manifestações de esgotamento definitivo do modelo taylorista, o qual, enclausurando-se nas paredes da fábrica, tinha feito nascer a hegemonia, e até o mito, da gestão cientifica, considerada indispensável para a otimização dos recursos da empresa. A crise deste modelo é significativa e atinge a própria divisão interna das mansões que vai sendo abandonada como fruto de uma visão simplificada e simplista dos mecanismos de renovação das qualificações nas empresas.

Em 1984, um congresso em Paris ${ }^{13}$ faz ressaltar o debate em torno das "Culturas de Empresa" como fenômeno surgido da 
necessidade de revigorar o potencial humano das empresas norteamericanas diante da concorrência japonesa. A cultura de empresa é uma problemática interessante para Sainsaulieu (1987), que busca responder a uma série de interrogativos teóricos de não fácil solução. $\mathrm{O}$ autor inicia analisando diversas hipóteses, apontando para cada uma os relativos problemas:

1) dizer que existe uma "cultura de empresa" poderia significar que as relações sociais na empresa se desenvolvem na base de representações mentais e valores articulados e coerentes, interiorizados pelos diversos atores. Esta visão choca-se com a visão do antagonismo de classe na empresa (reivindicação sindical e profissional) e com a própria história do desenvolvimento industrial; nesta visão antagônica, a possibilidade de uma cultura comum é vista como imposta pelo grupo dominante;

2) a empresa não seria mais somente um lugar para onde confluem diversas culturas específicas herdadas do passado, mas tornar-se-ia um centro de identidade única, e unificador com um projeto mobilizador para o qual cada um pode contribuir ou ao qual pode aderir. Neste caso, o problema é saber como passar de representações culturais compartilhadas entre os membros de uma comunidade para o engajamento efetivo em um projeto de realizações concretas;

3) a empresa seria uma instituição social que produz sociabilidade e identidades específicas no seio da sociedade. Teria valores, normas, símbolos próprios, instituindo formas particulares de se comportar, mecanismos de aprendizagem, de transmissão e de difusão dessa cultura na sociedade externa, independentemente de outras instituições, como a família, a escola, a Igreja. Neste caso, o problema é como conseguiria conciliar esta vocação institucional com a lógica econômica e os objetivos econômicos;

4) finalmente, falar de cultura significaria dizer que a empresa assegura a seus membros tanto os meios práticos de reconhecimento de uma identidade específica, como um 
potencial de criatividade e de integração para todos. No entanto, a história das sociedades industriais é tão marcada por conflitos de interesse, desigualdades, exploração, exclusão e alienação que estas hipóteses devem ser avaliadas com extrema cautela.

Assim, para o autor, as empresas não são ambientes homogêneos como, o conceito de cultura na tradição etnológica pressupõe, isto é, não se assemelham a nenhum dos âmbitos tradicionais de cultura, não são nem tribos, nem aldeias, nem famílias. Ao mesmo tempo, a história das sociedades industriais contém tantos conflitos de interesse, desigualdade de funções, exclusão e exploração alienantes que invalidariam a possibilidade de uma cultura homogênea. Portanto, mais do que a cultura de empresa, Sainsaulieu propõe considerar "as dinâmicas culturais das relações organizadas na empresa” (1987, p. 210). Nesta perspectiva, ele convida para a reflexão sobre um conjunto de formas de regulação cultural da empresa que são herdadas de uma longa história industrial e que devem ser ponderadas porque produzem efeitos sistemáticos e podem ser importantes em um processo de mudança e desenvolvimento (idem, p. 214). Tais formas, que aparecem como sendo "cultura de empresa", são:

\section{1) O "espírito-casa"}

Encontrado em empresas familiares ou paternalistas, baseia-se em forças externas à produção: a família, a comunidade local, a lealdade e a submissão aos valores destas. No interior dessa cultura não pode haver oposição duradoura, sob pena de exclusão da comunidade. As decisões industriais são tomadas tendo em conta a economia, mas também a comunidade local e a família. São muito fortes, justamente porque conseguem articular o social com o econômico.

\section{2) As “comunidades profissionais"}

Elas têm contribuído para a regulamentação cultural nas empresas, por exemplo as ordens dos engenheiros, advogados, 
médicos, pesquisadores, as quais, muitas vezes, impõem suas normas e valores à absorção dos profissionais pelas empresas.

3) As “culturas antagônicas"

Caracterizam a empresa que tem história de longos e fortes conflitos sociais, que as levaram a instituir uma certa democracia industrial e a negociação coletiva. Nesse caso, são as forças sociais externas à empresa que influenciam o sistema social de produção, porém sem poder converter o sistema social de luta em sistema social de produção.

\section{4) As "culturas burocráticas e estatutárias"}

Estas culturas não concentram a atenção no ofício, na família ou na mobilização social, mas sobre o complexo conjunto humano definido pela estrutura técnica e pela organização das funções. Estas culturas suprimem as relações pessoais, impõem relações formais e hierarquizadas, não são sensíveis às representações coletivas que vêm de fora da empresa, reduzem as comunidades profissionais a estratos ligados à função e não ao ofício, definem um sistema fortemente centrado sobre si próprio.

\section{5) Os "fundamentos culturais do taylorismo"}

Tais fundamentos desenvolvem uma identidade com o trabalho somente entre os quadros e os profissionais, e não entre os trabalhadores. São dimensões que opõem os ofícios aos setores técnicos e também as identidades que dessa oposição resultam. $\mathrm{O}$ imperativo da racionalidade leva a se concentrar sobre os ajustes internos à empresa em detrimento das entidades externas (família, comunidade local, nação).

\section{6) As “culturas do ator"}

Elas sublinham que o sistema é formado pelas pessoas e todas elas sentem-se parte de uma ação coletiva. Comportam significativas 
mudanças nas relações interpessoais: abrem espaço para entrevistas diretas com os chefes, favorecem a formação de grupos expontâneos e duráveis, criam afinidades interpessoais, transformam os processos decisórios em processos interativos. Nessa ótica, há nas análises sociológicas, de um lado, uma impressão geral de justiça social, de liberdade e de otimismo e, de outro, uma crítica no sentido de que os operários não participam das decisões e a manutenção do poder seria, de fato, a verdadeira relação entre estratégias e objetivos. Sainsaulieu considera que a "cultura do ator" pode até ser um começo de uma verdadeira cultura de empresa (porque permite a coexistência de grupos culturais diversos, podendo articular as diferenças entre eles em ações estratégicas úteis à empresa, não somente dentro da mesma, mas também fora dela, com clientes, com concorrentes, com bancos ou com o Estado), no entanto, apresenta alguns problemas. Um é que em face de uma conjuntura de estagnação, as alianças se congelam e os objetivos se restringem à defesa do que já é adquirido pelos grupos; outro problema é que esta cultura não é estável, já que não há lealdade nem adesão duráveis nas comunidades profissionais; outro ainda é que a identidade com o trabalho é forte somente entre os quadros superiores, enquanto é muito frágil nos estratos sem poder. ${ }^{14}$

\section{7) A “empresa do mercado"}

Ao contrário das culturas que privilegiam as estruturas internas da empresa e observam como secundários o mercado, os clientes e os produtos, esta forma busca fundar uma imagem a partir de elementos que se comunicam com o mercado, tais como a qualidade do produto, uma filosofia da empresa, um estilo comercial. Esta imagem torna-se o fundamento de uma cultura na qual todos os que trabalham estão inseridos e para a qual suas ações têm de contribuir. Produção e qualidade do produto se colocam como objetivo que vai mais além do trabalhador (exemplo japonês). O problema é que essa preocupação historicamente sempre foi do "patrão" ou de certos setores especiais da empresa e nunca da massa dos trabalhadores.

8) As "culturas de funcionamento coletivo"

Estas nasceram intelectualmente do utopismo francês e, politicamente, da Resistência, tendo sido revitalizadas pelas 
experiências de autogestão e das cooperativas operárias após os movimentos de 1968. Para Sainsaulieu, os estudos mostram que três processos estão misturados nessas experiências. O primeiro é a visão de equipe, onde as decisões em comum produzem importantes trocas e aprendizagem cultural e onde novas identidades se afirmam e trabalhadores antes marginalizados voltam a se sentir parte do conjunto. $\mathrm{O}$ segundo é a confrontação de diferenças (entre jovens e velhos, entre homens e mulheres, entre profissões) que estimula a comunicação, que obriga a enfrentar as diferenças, abrindo o debate sobre o trabalho e as diferenças culturais. O terceiro é dado pelas experiências efetivas de autogestão e de trabalho coletivo. Estas, porém, são pequenas ilhas no meio do fordismo e do taylorismo e provocam desconfiança ao seu exterior, nos clientes, fornecedores, técnicos e fiscais.

\section{9) A "cultura de desenvolvimento social de empresa"}

Seu aspeto mais peculiar concerne à articulação da pluralidade cultural e da confrontação de identidades específicas. Torna-se uma cultura de desenvolvimento social e democrático, no sentido de que produz a coexistência das diferenças, apresentando-se como o lugar do pluralismo. Tal cultura impõe à empresa a necessidade de se abrir ao meio externo do qual depende. Quem trabalha na empresa deverá conhecer não somente seus colegas, mas também o meio social no qual a mesma está inserida.

Da análise cultural da empresa, Sainsaulieu pode tirar algumas lições. A primeira é que toda mudança social não pode evitar a modificação das regulações anteriores, mas também não pode ignorar as bases das identidades dos atores. A segunda é que a empresa é um lugar onde se encontram diversas culturas saídas de grupos e instituições que estão no seu ambiente. Porém não é um simples receptáculo de culturas diversas, nem somente um lugar de conflitos e de jogos de poder, mas é um lugar de transformação cultural pelo tempo e pela intensidade das relações humanas. Finalmente, falar de cultura de empresa significa ir mais além da cultura da organização (maneiras de agir, controlar, comunicar e decidir). Nela está englobada também a vontade de empreender projetos coletivos de produção e o 
sentimento de pertencer ao mesmo coletivo humano. $\mathrm{O}$ autor conclui que, apesar da nossa realidade estar muito longe disso, as análises nos mostram quanto as empresas estão ligadas ao seu meio social e quão importante é não observá-las como meras "ilhas sociotécnicas"

\section{À guisa de conclusões}

A noção de racionalidade, referência inicial desta reflexão, permite problematizar as relações complexas existentes entre as dinâmicas econômicas e sociais em um processo de mudança. Nesse sentido, os vínculos entre racionalidade, cultura e espírito empresarial, permitem deslocar o enfoque dos estudos em termos de "empresa e sociedade" para uma perspectiva que observa a "empresa na sociedade". Assim podemos enfatizar as seguintes proposições.

- A noção de interesse, de fato, mobiliza e organiza os agentes econômicos porém, se de um lado pode englobar todas as aspirações humanas, por outro, permanece uma noção que só ganha sentido se for dimensionada historicamente e, conseqüentemente, acaba se confrontando com a multiplicidade das relações entre os valores e a economia.

- O conceito de "modernidade" não implica necessariamente na uniformidade, nem na ruptura com o passado; poderia expressar também a adaptação à mudança pela capacidade de combinar elementos novos com partes da tradição. A noção de "espírito empresarial" tem sido concebida como representando a capacidade de introduzir "a novidade" porém, muitas vezes, o novo consiste em conseguir recuperar e combinar práticas antigas com as dimensões novas de um contexto social significativamente modificado. A base constitutiva dos empreendimentos capitalistas são os bens econômicos, que constituem a infra-estrutura produtiva, e o capital cultural, que assegura seu funcionamento e sua reprodução. A lógica de acumulação destes fatores nem sempre e nem necessariamente segue os princípios teóricos da escolha racional, nem simplesmente visa à mera expansão da atividade empresarial. De fato, pode-se desenvolver um 
comportamento no qual o ator seleciona e escolhe, entre diferentes oportunidades, seguindo um cálculo estratégico no qual são tomados em conta os lucros e as perdas nos diferentes níveis, econômico, político e simbólico.

- O "espirito empresarial", como a expressão da racionalidade capitalista, permaneceu muito tempo restrito às estratégias produtivas. Esta noção pode ser enriquecida por uma outra, mais ampla, que inclui as dimensões culturais da empresa, isto é um conjunto de práticas e valores fundados em referências advindas de diferentes ambiente: familiar, territorial, político e social. Tais ambientes atuam tanto na racionalidade organizativa no interior da empresa, estabelecendo hierarquias não necessariamente funcionais (entre trabalho manual e inteletual, entre homens e mulheres, entre raças), como na racionalidade empresarial nas mais amplas relações sociais estabelecidas pelos empresários junto aos fornecedores, consumidores, clientes e ao meio ambiente (valores éticos, responsabilidade social, responsabilidade ambiental).

- As empresas não podem ser vistas exclusivamente sob a ótica organizacional, já que estas são inseridas na cultura de uma sociedade, de uma região, e ligadas a culturas profissionais que são sensíveis à sua organização e que podem reagir ou intervir em suas mudanças. Isto reafirma a idéia de que a empresa, além de um sistema econômico e técnico, é um sistema social e como tal, absorve o que outras instâncias sociais, como a escola, a família e o território, lhe oferecem como referências. Com certeza a empresa também consegue ter influências sobre diversas dimensões da vida social, mostrando capacidade de elaboração cultural, isto é, capacidade de estabelecer elos e trocas com as instituições, grupos e comunidades. Assim a empresa se apresenta como cenário expressivo por ser um contexto permeável para absorver, reproduzir, responder e movimentar as representações simbólicas elaboradas pelos atores, os empresários, os trabalhadores, as trabalhadoras, as organizações sindicais, os clientes e fornecedores e demais interessados. 


\section{Notas}

1 Esta reflexão teórica é parte da pesquisa Os herdeiros: a transmissão dos patrimônio econômicos e culturais e a atualização da profissionalidade, coordenada por Paola Cappellin, com apoio do CNPq, na qual foram analisadas as transformações ocorridas nas empresas familiares de porte médio e tradicionais, nos municípios de Petrópolis e Teresópolis.

2 A convivência de diferentes estilos empresariais, à luz das dimensões da mudança e/ou da continuidade, podem revelar grande parte de seus aspectos problemáticos se observados no âmbito da passagem entre gerações. É nessa passagem que a transmissão dos patrimônios econômicos e culturais e a atualização das profissionalidades se constituem como campo privilegiado de interação entre o velho e o novo. Por isso, um dos principais objetivos de nosso estudo é procurar os elementos de ruptura e de continuidade entre as duas últimas gerações de empresários, problematizando as formas de reprodução das organizações produtivas, elementos esses que têm contribuído para a caracterização da economia no território de atuação da empresa.

3 Na explicação do surgimento do capitalismo moderno, o autor se refere às afinidades eletivas como sendo a combinação de um ethos religioso com o espírito de um sistema econômico.

4 Albert Otto Hirschman nasceu em Berlin em 1915; formado em Filosofia, economista de profissão, de convicções socialistas, deixou a Alemanha em 1933. Participou da elaboração do Plano Marshall e foi professor em Princeton. Entre 1952 e 1956 foi conselheiro econômico do Governo da Colômbia, e a principal lição tirada desse período é a de que as forças não de mercado não são necessariamente menos autênticas do que as forças do mercado. Dedicou dezoito anos ao estudo da Economia do Desenvolvimento e à América Latina (ver Mendolesi, 1990).

5 Mandeville (1670-1733), autor da famosa Fábula das abelhas (1705), dá-nos um exemplo claro dessa idéia. Conta de uma colmeia que era próspera, mas viciosa; quando se lhe impôs uma moral, acabaram os vícios e também a prosperidade. O subtítulo, Vícios privados e públicos benefícios, exprime a idéia do autor segundo a qual o fundamento da sociedade não está na sociabilidade, nos sentimentos benevolentes, nas virtudes da raça e da abnegação; está, ao contrário, no que chamamos de "mal", moral ou natural; é o natural desejo de riqueza que faz florescer o comércio e a indústria. É desta visão que também deriva a idéia de que o luxo faz crescer o consumo e a riqueza. 
6 Georg Simmel (1858-1918) mais que um sociólogo, foi considerado um filósofo, um psicólogo, um esteta. Todas as suas obras têm um forte componente psicológico. Mesmo que busque fundamentar a Sociologia como uma disciplina independente, acabará confessando que ele é filósofo e que a Sociologia interessa-lhe enquanto subsídio para a Filosofia. Paradoxalmente, depois de sua morte resta muito do sociólogo e bem pouco do filósofo. Demostrou sempre ter muitos interesses, conduzidos com muita personalidade, não podendo ser enquadrado em nenhuma das correntes conhecidas.

7 No último capítulo da obra, em que analisa diferentes modos de experimentar a modernidade, há também uma teoria da alienação cultural bastante próprima à de Marx.

8 Thorstein Veblen (1857-1929), filho de agricultores migrantes noruegueses do Winsconsin, foi professor de Economia em Chicago, Stanford e Missouri. É considerado uma das mentes mais criativas da América, mas não se consegue enquadrá-la em nenhuma corrente teórica e nem mesmo disciplinar; para os sociólogos era economista; para os econimistas era sociólogo.

9 A distinção entre cultura pacífica e belicosa, correspondentes respectivamente aos estágios comunitários e bárbaros, é mais uma diferenciação típico-ideal de que histórica. Para Veblen esta diferença se funda na atitude pacífica ou de luta que prevalece no senso comum quando julga os fatos, os eventos e as relações sociais.

10 Jon Elster, nascido em Oslo, em 1940, formado em Filosofia, interessase $\log$ o pela teoria da ação intencional e pelo marxismo. Em meados de 1970, vai para os EUA e, em 1979, faz parte, junto com o filósofo Cohen, o economista Roemer e outros, do chamado September Group que, em 1986, se autodenomina de "marxistas analíticos". Discutem de Marx: o conceito de exploração, a crítica ética ao capitalismo, a centralidade da luta de classe na transição histórica. Consideram que o marxismo não tem um método próprio de análise e, por isso, assumem o "individualismo metodológico" contra o holismo, isto é, partem do pressuposto de que todos os fenômenos sociais são explicáveis em termos de indivíduos, suas propriedades, suas crenças. Atualmente, ensina Ciências Políticas e Filosofia na Universidade de Chicago.

11 Lembramos que, para Weber (1944), a ação racional com relação aos fins é a única realmente racional, sendo que a ação racional com relação aos valores é racional só na escolha dos meios e sempre aparece irracional do ponto de vista da primeira. De qualquer maneira, a absoluta racionalidade 
com relação aos fins é um caso limite de caráter essencialmente construtivo. Os indivíduos reais que agem de maneira mais próxima são, para Weber, os empresários.

12 A Teoria dos Jogos foi formulada por Von Neuman e Morgenster (1944). Os autores questionavam a visão econômica que pressupunha uma relação direta entre os agentes e o mercado, propondo que se observassem as relações econômicas como inter-relações entre agentes, todos eles racionais. Esta teoria viveu 10 anos de sucesso, sendo em seguida posta de lado. Reapareceu nos anos de 1970, no estudo das relações internacionais, na teoria política e, timidamente, na Sociologia.

13 Organizado pela Fundation Nationale pour l'Enseignement de la Gestion de la Entreprise (FNEGE). Sainsaulieu (1987, p. 214) aponta como decisivas as intervenções publicadas na Revue Française de Gestion, n. 47-47, Set. 1984.

14 Outros autores abordam a questão na perspectiva da "cultura do trabalho". A empresa pode ser vista também como um espaço onde se plasma a preparação profissional e uma "ética" profissional. Neste sentido, a unidade produtiva tornar-se-ia um ambiente importante de integração e de socialização do saber (Capecchi, 1980; Butera, 1989). A cultura do trabalho, revela toda sua complexidade e plasticidade na expressiva valorização dada ao saber técnico, sobretudo nas fase reorganização da atividade empresarial. Mas também a cultura do trabalho se revela no normal funcionamento da empresa e, particularmente, na configuração da divisão do trabalho (Sabel, 1985). Na própria unidade produtiva, os recursos investidos nos planos de carreiras, na requalificação e atualização dos quadros técnicos, são todos elementos indicativos da preocupação de renovar e/ou preservar a cultura do trabalho. A organização técnicoprodutivo-administrativa e sua correspondente divisão sexual do trabalho podem evidenciar os conteúdos simbólicos desta cultura (Pesce, 1990).

Abstract: The essay deals with the connection among the notions rationality, interest, values, and culture. In the weberian sociology, rationality is associated to the modern capitalism and to the "entrepreneurial spirit". Other authors (Off, Hirschman, Veblen, Simmel, Elster) discussed how difficult is to joint the modern and the rational. Their analyses lead to some questions, which are relevant to the study of firm issues. Firstly, the development of the capitalism really imposed and universalized the economic rationality, but it did make this process neither homogeneous, nor independent from the 
culture influence. Secondly, values affect the economic rationality creating norms and rules, those orient actions and initiatives in order to maintain the patrimony and have profits. It is possible to speak about "firm culture" that leads to consider the firm's cultural regulations forms. Such regulations are inherited from a long industrial history and have to be understood because they produce systematic effects. The "entrepreneurial spirit", as the capitalistic rationality expression, can be enriched by larger dimensions including values and practices coming from different cultural environments, such as family, community, political and social organizations. In conclusion, firms cannot be seen on the only organizational optic, because they are part of a regional and social culture and they are linked to professional cultures and their organizations. In addition, firms are able to affect different dimensions of the social life, setting-up links and exchanges with institutions, groups, and communities.

Key words: Sociology of the Firm, rationality.

Résumé: L' article porte sur le lien entre les notions de rationalité, d'intérêt, de valeurs et de culture. Dans la sociologie weberienne, la rationalité est associée au capitalisme moderne et à l' "esprit d'entrepreneur". D' autres auteurs (Off, Hirschman, Veblen, Simmel, Elster) traitent de la difficulté de réunir le moderne et le rationnel. Leurs analyses conduisent à certaines questions incontournables pour l'étude de la firme. Tout d'abord, le développement du capitalisme a imposé et universalisé la rationalité économique, mais il n'a pas rendu ce processus homogène ni indépendant de l'influence de la culture. Ensuite, les valeurs affectent la rationalité économique en créant des normes et des règles, qui orientent les actions et les initiatives dans le but de garantir le patrimoine et les profits. Il est possible de parler de "culture de la firme", ce qui conduit à prendre en considération les formes de régulation culturelle de la firme. De telles régulations proviennent d'une histoire industrielle longue et doivent être comprises car elles produisent des effets systématiques. L'"esprit entrepreneurial", comme expression de la rationalité capitaliste, peut être enrichi par de plus vastes dimensions qui incluent les valeurs et les pratiques provenant de différents environnements culturels, comme la famille, la communauté, les organisations politiques et sociales. En conclusion, les firmes ne peuvent être saisies uniquement sous l'angle organisationnel, car elles font partie d'une culture régionale et sociale et tissent des liens avec les cultures professionnelles et leurs organisa- 
tions. En outre, les firmes peuvent affecter différentes dimensions de la vie sociale, en établissant des liens et des échanges avec les institutions, les groupes et les communautés.

Mots-clés: Sociologie de la Firme, rationalité.

\section{Referências Bibliográficas}

BERNOUX, P. La sociologie des entreprises. Paris: Seuil, 1995.

BUTERA, F. Dalle occupazioni industriali alle nuove professioni. Milano: F. Angeli, 1989.

CAPECCHI, V. Classe operaia e cultura borghese: ipotesi di una ricerca in Emilia-Romagna. In: Famiglia operaia, mutamenti culturali, 150 ore. Bologna: Il Mulino, 1980.

CAPPELLIN, P.; GIULIANI, G. M. Os herdeiros: estudo de caso das empresas de porte médio da região serrana do estado do Rio de Janeiro. In: KIRSCHNER, A. M.; GOMES, E. R. Empresa, empresário e sociedade. Rio de Janeiro: Sette Letras, 1999.

DINIZ, E.; BOSCHI, R. Empresariado nacional e Estado no Brasil. Rio de Janeiro: Forense Universitaria, 1993.

ELSTER, J. Ulysses and the sirens: studies in rationality and irrationality. Cambridge: Cambridge University Press, 1979. . Sour grapes: studies in the subversion of rationality. Cambridge: Cambridge University Press, 1983. . Solomonic judjements. Cambridge: Cambridge University Press, 1989.

. Peças e engrenagens das Ciências Sociais. Rio de Janeiro: Relume Dumará, 1994.

FAORO, R. Os donos do poder: formação do patronato político brasileiro. São Paulo: Globo, 1989.

HIRSCHMAN, A. As paixões e os interesses. São Paulo: Paz e Terra,1979.

GIDDENS, A. As conseqüências da modernidade. São Paulo: Editora Unesp, 1991.

MENDOLESI, L. Introdução. In: HIRSCHMAN, A. Come far passare le riforme. Bologna: Mulino, 1990. 
MOREL, R. L. et al. Perspectivas do Sindicalismo no Rio de Janeiro hoje: o debate em torno do contrato coletivo do trabalho. ENCONTRO ANUAL DA ANPOCS, 17. [Anais...]. 1993.

OFFE, C. L'utopia dell'ópzione zero. In: Ecologia e politica. Milano: Feltrinelli, 1987.

PESCE, A. Un'altra Emilia Romagna: rapporto reginale I. Bologna: E. R. F. Angeli, 1990.

SABEL, C. F. Trabajo e politica. Madrid: Ministerio de Trabajo e Seguridad Social, 1985.

SAINSAULIEU, R. Sociologie de l'organization et de l'entreprise. Paris: Presse de Fondation Nationale des Sciences Politiques, Dalloz, 1987.

SEN, A. Sobre ética e economia. São Paulo: Companhia das Letras, 1999.

SCHUMPETER, J. Capitalismo, socialismo e democracia. 1954.

SIMMEL, G. La filosophie de l'argent. Paris: Ed. PUF, 1987.

TOURAINE, A. Le retour à l'acteur. Paris: Fayard, 1984.

VEBLEN, T. La teoria della classe agiata. Torino: Einaudi, 1969. Obra original: The theory of the leisure class, 1899.

VON NEUMAN; MORGENSTER. Teoria dos jogos e comportamentos econômicos. 1944.

WEBER, M. Economia e Sociedade. México: Fundo de Cultura Economica, 1944. 